\title{
Estudos do Jornalismo: reafirmação do status quo ou busca por arranjos alternativos?
}

\author{
Cláudia Nonato \\ Escola de Comunicação e Artes \\ da Universidade de São Paulo \\ claudia.nonato@uol.com.br \\ Olívia Bulla \\ Escola de Comunicação e Artes \\ da Universidade de São Paulo \\ oliviabulla@gmail.com
}

\begin{abstract}
Resumo
O presente artigo pretende discutir as relações de trabalho do jornalista do ponto de vista da produção jornalística e apresentar influências das rotinas produtivas na construção de um fato, bem como viabilizar alternativas capazes o fazer Jornalismo. A partir do binômio Comunicação e Trabalho, que busca compreender redes de sentido em um mundo do trabalho em permanente mudança, a discussão mostra que a racionalidade dos processos produtivos modifica a condição do trabalhador. Como exemplo, serão apresentadas duas pesquisas: a primeira mostra a forma como os números são usados para sustentar um discurso na notícia, por considerar que as rotinas de trabalho e as práticas produtivas permitem, e até incentivam, ao jornalista usar esse recurso na interpretação dos fatos sociais; a segunda mostra que portais, blogs e ferramentas das redes sociais são hoje utilizados como 'inovações na forma de produzir Jornalismo', e discute como 'arranjos econômicos' podem viabilizar o trabalho do jornalista sendo encarados como possibilidade de mudanças nas rotinas produtivas e incorporados como alternativos ao trabalho jornalístico tradicional. Com isso, propõem-se mostrar a complexidade da discussão sobre o trabalho do jornalista, os desafios dos arranjos econômicos e a viabilidade de sustentação de tais iniciativas. Ao final, os resultados das duas pesquisas reafirmam a relevância dos estudos da comunicação no mundo do trabalho.
\end{abstract}

Palavras-chave: Jornalista; Jornalismo; relações de trabalho do jornalista; comunicação e trabalho; mundo do trabalho.

\section{Abstract}

This article discusses the journalist's labor relations from the perspective of journalistic production and present the influences of productive routines in the construction of a fact, as well as viable alternatives able to innovate the way they do journalism. From the binomial Communication and Works, which seeks to understand the sense of networks in a work world 
in constant change, the discussion shows that the rationality of production processes modifies the worker's condition. As an example, two surveys will be presented: the first shows how numbers are used as a speech in the news, considering that work routines and production practices allow, and even encourage, the journalist use this feature in the interpretation of social facts; the second shows that portals, blogs and social networking tools are now used as 'innovations in the way of producing journalism', and discusses how 'economic arrangements' are seen as a possibility for changes in production routines, and incorporated as alternative to traditional forms of journalism. With this, they propose to show the complexity of the discussion on the work of journalists, the challenges of economic arrangements and the feasibility of sustaining such initiatives. In the end, the results of two studies reaffirm the relevance of communication studies in the world of work.

Keywords: Journalists; journalism; labor relations of the journalist; communication and work; world of work.

\section{Introdução}

A discussão a ser apresentada parte da dimensão do trabalho do jornalista e da prática da atividade jornalística, vendo-o como mediação fundamental da comunicação. Considera-se que só assim é possível relacionar os conceitos empregados com a produção da notícia.

Dito isso, pode-se avançar no sentido de mostrar, empiricamente, a forma como as rotinas de trabalho e as práticas produtivas influenciam na interpretação dos fatos sociais e na veiculação de notícias. Por um lado, tem-se o fazer jornalístico nas empresas tradicionais, que usam de estratégias persuasivas desviantes, como a construção de um discurso que reafirma o status quo a partir dos números, silenciando vozes e versões dissidentes sobre um mesmo fato noticioso.

Por outro, tem-se os blogs de jornalistas que buscam o exercício de um Jornalismo alternativo à grande empresa, em busca de maior autonomia, independência, liberdade de expressão e realização profissional. Com o objetivo de apreender os novos arranjos que possibilitem o pleno exercício do profissional, a discussão neste artigo passa pelo papel da pressão econômica e da censura, que freiam a possibilidade de iniciativas que poderiam ser significativas para a renovação do Jornalismo.

O referencial teórico das duas pesquisas a serem apresentadas conceitua o trabalho e a comunicação como atividade humana, no sentido ontológico do ser social, destacando como os processos produtivos foram transformados pela organização das rotinas produtivas. Marx e Engels ([1932]2010) afirmam que o trabalho é o que diferencia o homem dos outros animais, sendo que "o trabalho produtivo se determina a partir do ponto de vista da produção capitalista" (p. 151). 
Nessa visão, a riqueza das sociedades, em que domina o modo de produção capitalista, aparece como uma "imensa coleção de mercadorias". Mas o que importa são as relações nesse processo material de apropriação da natureza pelos seres humanos, nos atos de produção e consumo, para satisfazer as vontades e necessidades, separados pela troca. Assim, as relações materiais, que nada mais são que as formas necessárias nas quais se realiza a atividade material e individual, formam a base de todas as relações sociais. Mas como lembram Marx e Engels ([1932]2010), "as ideias da classe dominante são as ideias dominantes" (p. 113) e a comunicação se vê acorrentada à ordem social reinante, representando um conflito. Nesse embate, os representantes da cultura dominante impõem seus valores, desmotivando o diferente.

Como exemplo, o artigo mostra como os números são usados para simular um sentido na notícia, sendo usados como estratégia persuasiva desviante, devido à aparente força de objetividade, ofuscando outros argumentos mais relevantes sobre os fatos. O número também revela as rotinas produtivas, que legitimam a cobertura editorializada de um fato, engendrando a autocensura e contaminando o fazer da notícia.

Já nos blogs, os jornalistas que buscam o exercício de um Jornalismo alternativo à grande empresa dizem respeito, sobretudo, à qualidade jornalística, à credibilidade e à visibilidade, trazendo novos desafios aos processos comunicacionais, pois é nesse "mundo", de blogueiro, que o trabalho adquire outros sentidos e os processos de comunicação para a organização da produção influenciam nas transformações das formas de trabalhar e de se relacionar socialmente.

Portanto, a análise se dá no sentido de compreender como os elementos linguísticos e extralinguísticos - aspectos históricos, sociais, culturais, ideológicos - se relacionam na produção de sentido da notícia. Nela, a comunicação é um processo em que a estrutura simbólica é mediada pelo próprio contexto social, permeado pelas contradições e conflitos relativos ao momento histórico vivido.

Já a abordagem ergológica (Schwartz) permite estudar as relações de comunicação no mundo do trabalho, um espaço-chave para o estudo das relações humanas e lugar de mediação e de construção da subjetividade. A partir da perspectiva ergológica, é possível problematizar o objeto de estudo de maneira mais complexa, destacando a relevância dos sujeitos na transformação social.

Sob essa ótica, Rüdiger (2011) explica que a produção e o trabalho são os fatores de desenvolvimento da comunicação, da linguagem e da consciência. Os processos de mediação simbólica da realidade são vistos como elementos que são condicionados pelo modo de produção imperante na sociedade. "O trabalho representa, portanto, o fundamento da interação simbólica. A comunicação, em última instância, é a mediação primária do trabalho" (ibid, 2011, p. 80). 


\section{Os números reafirmando o status quo}

A partir da perspectiva que considera as funções externas responsáveis pela organização interna do sistema linguístico, analisou-se como os números servem de argumento para a objetividade e, ao mesmo tempo, comunicam a ideologia. Nesse protagonismo do sujeito, a linguagem não é transparente, pois abriga vários sentidos, conota valores iguais, parecidos, diferentes ou opostos vistos não isoladamente, mas em em um dialogismo (Bakhtin) entre os coenunciadores.

No processo de produção da notícia há diversos modos de se dizer e, consequentemente, diversas formas de se interpretar o que é dito. Nele, os números ganham a aparência de fatos e são aceitos sem questionamento, pois ele parece preciso - eleito o eixo entre o discurso da organização e a prática cotidiana.

É esse fato que a pesquisa "A evidência dos números no discurso jornalístico através das relações de comunicação e trabalho" (BULLA, 2015) procurou explicar a partir da busca nas teorias sociais, das influências e do contexto que dão significado cultural aos números, pois "a sociedade está acostumada a ouvir e repetir que os números não mentem jamais" (PULITI, 2013, p. 27). Porém, esse consenso, em geral, é equivocado.

Seife (2012) explica que "os cálculos provocam um curto-circuito no cérebro" (ibid, p. 12), tirando toda a capacidade crítica do cidadão. Isso ocorre porque "o mundo frio e cristalino dos algarismos nos oferece o que há de mais raro: a certeza absoluta" (ibid). Portanto, "não importa o quanto uma ideia seja inacreditável, os números podem lhe conferir credibilidade" (ibid). Esses dois quesitos que o número carrega - objetividade e credibilidade - são fundamentais para o Jornalismo.

A fim de identificar essa "aura de plausibilidade" conferida aos números foi selecionado um corpus, composto por matérias publicadas no jornal O Estado de S. Paulo, doravante Estadão, sobre as manifestações contra o aumento da tarifa de transporte público em São Paulo, em junho de 2013, e seus desdobramentos. Um ano depois, foi coletada uma segunda amostra, quando protestos foram retomados em meio à Copa do Mundo no Brasil.

A escolha do jornal se deu pela facilidade para levantar o material empírico necessário, devido ao vínculo profissional em uma das empresas do grupo, na época. A análise desse corpus foi feita sob a ótica da presença do Outro e com um discurso clivado pelas ideologias.

A avaliação foi confrontada com as observações das rotinas produtivas dos jornalistas, por meio de entrevistas com cinco autores apontados entre os que mais se repetem nas reportagens selecionadas. Tal processo metodológico permitiu entender como o produto jornalístico derivado dos números é tratado e como se dão as decisões que marcam o valor do número e sua representatividade na notícia.

É válido lembrar que os protestos de junho de 2013 surgiram, inicialmente, para contestar o aumento de $\mathrm{R} \$ 0,20$ na tarifa de transporte público em São Paulo. Mas os atos foram ganhando apoio popular, o que elevou a pauta de reivindicações. 
Como consequência, Frederico (2013) afirma que o indivíduo ficou "enredado no campo dominado pela mídia", que visava "pautar a conduta individual" (p. 252). Tanto que, "não foi por mero acaso que a palavra de ordem gritada nas ruas - 'vem pra rua, vem!' - tenha replicado o slogan da propaganda de uma marca de carros que então era veiculada exaustivamente na TV" (ibid).

Chauí (2013) avalia que a reivindicação específica ocorrida em São Paulo, capitaneada pelo Movimento Passe Livre (MPL), foi vitoriosa sob dois aspectos: reduzir a tarifa de transporte público, de volta aos $\mathrm{R} \$ 3,00$, e definir a questão do transporte público no plano dos direitos do cidadão por meio "da explicitação (e não do ocultamento) dos conflitos sociais e políticos". Porém, esses problemas, como verificaremos a seguir, passaram ao largo da cobertura jornalística do Estadão.

A chamada de capa em 7 de junho de 2013 é dividida entre uma notícia econômica e a que se refere ao protesto ocorrido na noite anterior "contra tarifa" de transporte público, que cessou o direito das pessoas (e dos carros) de mover-se e que acabara "em depredação e caos em SP" (BULLA, 2015, p.58). No texto, os números são o recurso que informa a presença "de cerca de mil pessoas contra o aumento da passagem de ônibus e metrô de $R \$ 3,00$ para $R \$$ 3,20" que "parou o trânsito de algumas das principais vias" da cidade "no horário de pico" (ibid). A linha fina do jornal dizia que "manifestantes fecharam avenidas, invadiram shoppings e deixaram rastros de destruição" (ibid). Tal cenário criado buscava ainda qualificar os personagens, dizendo que "pelo menos 50 pessoas ficaram feridas e 15 foram detidas" (ibid). Ao lado, uma foto intitulada "vandalismo" na legenda (ibid).

Apenas nesse trecho inicial é possível perceber o papel dado aos números na notícia. Para o Estadão, o primeiro dia de protesto contra o aumento da tarifa de ônibus e metrô levou "caos" e "depredação" à cidade, causando um dos piores índices de congestionamento do ano. "Às 19h, havia $160 \mathrm{~km}$ de lentidão - a média é 138 km", comparava o texto (ibid). A mesma reportagem traz ainda um boxe, ao final da segunda coluna, dizendo que o aumento da passagem de transporte público foi de 6,7\%, "menor que a inflação acumulada desde o último reajuste, de 14\%" - o que, portanto, não justifica tanto "vandalismo" (BULLA, 2015, p.59).

Já a versão dos jornalistas mostra que as manifestações de junho de 2013 demandaram dos profissionais entrevistados um tipo de cobertura que, até então, não era foco do jornal. "Junho foi algo completamente atípico, foi algo completamente diferente" conta Bruno Paes Manso, um dos mais experientes (BULLA, 2015, p. 132).

Tal despreparo, porém, não se dava pelo ineditismo no fato em si. "Não era uma novidade pra gente, em tese", diz Manso. "Era um assunto que não costumava inclusive ser coberto pelo jornal", pois viam "os 'malas' do MPL como um protesto a mais dentre as dezenas que acontecem na cidade" (ibid).

Nesse relato do profissional, o primeiro a ser entrevistado, é possível aferir a linha editorial do Estadão ecoada na fala do jornalista. Afinal, nem o jornal nem seus empregados 
demonstravam interesse na cobertura das manifestações feitas pelos "'malas"' do MPL, que já haviam incomodado outros prefeitos com a principal reivindicação do movimento, a tarifa zero. O assunto era algo que, "inclusive", não era um assunto "coberto" pelo jornal, afirma o jornalista em uma recorrência semântica que "inclui" o sujeito pertencente ao jornal, à empresa, ao mesmo tempo em que "exclui" aquele que também se sente assim na sociedade.

Caberia ao profissional trazer ao cidadão os elementos sobre a situação da sociedade, naquele momento. Mas o que se viu foi um enquadramento da empresa midiática a partir do "óculos social" (Schaff), ou os modelos e os padrões perceptivos com os quais os indivíduos enxergam o mundo, criando estereótipos.

Ao fazer assim, o jornalista e a imprensa criam uma "realidade" que parece real, mas que, na verdade, fabrica os signos necessários para que o Jornalismo possa reafirmar os valores na sociedade para a qual a atividade serve. Essa percepção é ecoada no editorial de 8 de junho de 2013, o primeiro do jornal sobre o assunto, que repete, usando argumentos a partir dos números, que o protesto contra a tarifa não passava, como dizia o título, de "Puro Vandalismo" (BULLA, 2015, p. 59). Para o jornal, o dia 6 de junho de 2013 foi um "dia de fúria" (ibid).

Nesse contexto, destaca-se o poder do número como amplificador da notícia. "Protesto fecha Marginal e lentidão chega a 226 km", dizia a chamada de capa do jornal no mesmo dia 8, sobre o segundo dia de manifestações (BULLA, 2015, p. 64). Entre a linha fina e o texto da manchete, uma foto da Marginal do Rio Pinheiros que retratava as "cerca de 5 mil pessoas", que ajudaram a causar "o terceiro pior congestionamento do ano", bloqueando tal via "por 30 minutos" e entrando "em confronto com a PM pelo $2^{\circ}$ dia" (ibid). O jornal ainda compara o risco das "armas" utilizadas, "com pedras de um lado e gás lacrimogêneo e balas de borracha de outro", e dimensiona o fato: "A Polícia Militar estimou em 2 mil o número de manifestantes e a Guarda Civil Metropolitana, em mil. Organizadores falaram em cinco mil" (BULLA, 2015, p.65).

Caio do Valle, que cobriu as manifestações de 2013 da Redação, explica que os números têm importância para dar "dimensão, compor a matéria e contar a história", ainda que existisse um "confronto de dados, né?" (BULLA, 2015, p. 138). Bruno Ribeiro, entrevistado junto com Do Valle, brinca que "a Polícia pega o total e divide por dez e o MPL pega o total e multiplica por dez", diminuindo ou valorizando o protesto (ibid).

Do Valle diz ainda que "as demandas" dos manifestantes, de qualquer tipo de protesto, "tinham que ter um espaço maior" (ibid). Mas a ausência das reivindicações sociais no jornal "é porque, infelizmente, o Jornalismo de Cidades está acostumado a fazer esse tipo de cobertura. É mais o que o ato em si provoca do que o que se pede com esse ato" (ibid), assumindo que se trata de uma característica intrínseca do "Jornalismo de Cidades", tal qual é praticado hoje. 
Como resultado, diz Ribeiro, que vivenciou a experiência das manifestações de 2013 nas ruas, é que "os textos que saíram no jornal naquela época, eles estão, eles não condiziam... É muito claro, entre estar lá e ver o jornal do dia seguinte" (BULLA, 2015, p. 137). Portanto, todo o processo de produção da notícia, desde a apuração até o texto, é "contaminado" por uma "linha editorial clara", que parece ter uma figura espiritual de onipresença e onisciência, pois, segundo Ribeiro, mesmo não havendo nenhuma "orientação ideológica, política", "a gente", o jornalista, "sabe" o que deve ser considerado "no texto ou não".

Essa concepção de Jornalismo relacionada com as rotinas de trabalho permite enxergar a prescrição como algo que não se resume a uma simples transferência de normas, mas como uma construção de discurso social. O jornalista acaba reafirma a voz da empresa e faz escolhas consonantes à linha editorial.

"O problema é o 'Mesquitinha' que cada um leva dentro de si" (BULLA, 2015, p. 140), brinca Manso, citando uma frase do colega de trabalho Daniel Piza, morto em 2011, e que se refere à família Mesquita, maior acionista do Grupo Estado. Tal citação, de um renomado colunista e editor executivo do jornal, mostra como o jornalista não se reconhece na dicotomia capital versus trabalho. Ao ecoar a fala de Piza, Manso revela ainda as escolhas feitas no âmbito específico da atividade do corpo si (Schwartz) no trabalho, eximindo-se de sua tarefa maior, que é o compromisso com a informação, e passando a atender o que se julga conveniente à linha editorial do jornal..

E foi o que se verificou um ano depois, quando teve início a Copa do Mundo no Brasil. Apenas a manchete do Estadão em 12 de junho de 2014 retoma muitos elementos que foram observados sobre as manifestações de junho de 2013, pois assim como se posicionou contra a redução de $R \$ 0,20$ na tarifa de transporte público, o jornal também se coloca contrário à realização do evento futebolístico no país.

O título de capa daquele dia era: "Brasil é favorito em Copa contestada" (BULLA, 2015, p. 87). Por meio dos números, o jornal mostra que a "favorita" seleção verde-e-amarela chegava ao dia de estreia do "contestado" Mundial de Futebol após o governo "gastar $R \$ 26,5$ bilhões, mas parte das obras não ficou pronta ou sequer saiu do papel" e recorda ainda que a Fifa escolheu o país como sede do evento em 2007, "no 20 mandato de Lula, e agora enfrenta problemas na organização". Era a "Copa das Copas" com "muitas promessas não cumpridas desde o anúncio do Mundial" - e ainda tinham "protestos programados para hoje".

Percebeu-se, então, como os números foram sendo usados e transformados em notícia, sempre submetidos às necessidades de vendagem do jornal para a obtenção do lucro, sendo, por isso, limitados e delimitados por aspectos sociais, culturais e ideológicos. Ao não ser capaz de ser ator dessa transformação, o ser social tampouco é capaz de alterar os valores que constroem a sociedade, firmando aqueles já existentes. 
Assim, o princípio da renormalização da atividade de trabalho ocorre, mas reitera os valores sociais e ideológicos da linha editorial prescrita pelo jornal. O sujeito, nesse caso, produz um discurso que identifica e qualifica o que se pode chamar de alienação do jornalista frente ao seu próprio trabalho.

\section{Os blogs como arranjos econômicos alternativos}

No percurso da globalização, e suas consequências para a sociedade contemporânea, os avanços tecnológicos e comunicacionais, além da reestruturação produtiva do mundo do trabalho, trouxeram profundas mudanças, principalmente no fim do século XX. Nesse contexto, vivenciamos o surgimento das Novas Tecnologias Microeletrônicas de Informação e Comunicação (NTICS) das redes telemáticas e também da Cibercultura, que levou à emergência de novos tipos de trabalho e ocupações nascidas da Sociedade em Rede (Castells, 1999).

Por causa da introdução de novas tecnologias e da informatização de indústrias, do setor de serviços e das empresas de comunicação, os trabalhadores foram levados a adquirir novas habilidades. Para alguns autores, a era da informação também significou o avanço do trabalho imaterial, principalmente pelo crescimento dos postos de "trabalho intelectual", ou de "trabalhadores cognitivos".

Huws (2007, p. 2) diz que "nunca houve na história do trabalho mais trabalho material do que há precisamente agora", diante do alto consumo de matérias-primas e da produção de artefatos em todo o mundo. O que mudou foi a divisão do trabalho.

Desse modo, o jornalista que trabalha certa quantidade de horas para uma grande empresa capitalista produz informação, que é vendida, não importa se em um meio impresso ou digital, e se transforma em valor (mais-valia - trabalho não pago). Parte desse valor vai para a subsistência; as horas trabalhadas para produzir esse valor (tempo de trabalho necessário) são reembolsadas (pelo salário). E o restante é a mais-valia.

Se o jornalista (que nessa condição é um trabalhador produtivo), resolve mudar de situação e trabalhar por conta própria, ele está quebrando a cadeia produtiva da teoria? $\mathrm{E}$ quais são os novos valores que envolvem essa mudança?

Para Dantas (2014), o atual processo de produção das indústrias culturais envolve tanto o trabalho de profissionais implicados diretamente no processo, como artistas e jornalistas, por exemplo, quanto o trabalho da audiência, que disponibiliza o seu tempo e participação em eventos da atual Sociedade do Espetáculo (Debord, 2003). O lucro extraído dessa relação é identificado pelo autor como sendo a "mais valia 2.0", uma "apropriação de trabalho não pago, literalmente gratuito, através de um sistema de agenciamento social, via meios eletrônicos de comunicação, lineares ou reticulares, que se incorpora na produção de valor" (Dantas, 2014, p. 86). 
Além de mobilizar o trabalho gratuito, as redes sociais criam e difundem valores que são associados ao capital social (Raquel Recuero, 2009). Entre esses valores, importantes para a difusão de informações, destacam-se a reputação (autoridade), a credibilidade e a visibilidade (popularidade), que são, a nosso ver, fundamentais para acompanhar a lógica de trabalho do jornalista blogueiro. Esses valores são influentes porque as redes sociais "implicam mudanças bastante expressivas nos modos através dos quais esses valores são construídos e moldados", por causa da possibilidade de mensurar a quantidade de acessos hoje, e também "porque esses valores são bastante alterados quando trazidos para a rede" (2009, p. 130).

A instantaneidade protagonizada pelos novos meios de comunicação trazem novos elementos e maiores desafios para estes os jornalistas, que incorporaram e adotaram tais inovações nas rotinas profissionais também como alternativas. O jornalista, que é um observador do cotidiano onde quer que esteja, seja em casa ou no trabalho, encontra cada vez mais dificuldades para ser um profissional por inteiro. Ao mesmo tempo, pesquisas apontam que quase todos os jornalistas encontraram como alternativa a criação e manutenção de um blog, seja para reproduzir notícias, publicar textos opinativos ou investigativos.

Os blogs trouxeram uma sensação de liberdade e revitalização do Jornalismo, tanto pela mudança na produção, quanto na plataforma discursiva. No novo meio, o jornalista escreve sobre o que gosta, assume integralmente o papel de formador de opinião, com a possibilidade de aprofundar a notícia; ele também pode simplesmente compartilhar um texto com outras pessoas; tem a instantaneidade e rapidez da Internet a seu favor e ainda conta com o feedback do leitor/receptor. Para Luís Martino, "os blogs desestabilizam algumas certezas da prática jornalística e colocam em questão algumas ideias consagradas a respeito do interior da profissão, de um lado, e da amplitude dos efeitos do Jornalismo no espaço público, de outro" (2009; p. 271).

Diante de tais constatações que o estudo "Jornalistas, blogueiros, migrantes da comunicação: em busca de novos arranjos econômicos para o trabalho jornalístico com maior autonomia e liberdade de expressão" (Lima, 2015) partiu de duas hipóteses: a) os profissionais do Jornalismo com vasta experiência na profissão estão migrando para novas mídias, principalmente para blogs independentes; e b) jornalistas experientes migram para os blogs em busca de maior autonomia, liberdade de expressão e realização profissional.

O estudo, realizado entre 2011 e 2014, observou as rotinas e produção dos jornalistas nos próprios blogs; pesquisou artigos de sites especializados em Jornalismo, e também artigos de revistas científicas; pesquisas acadêmicas (teses e dissertações) e analisou entrevistas de material primário e secundário com jornalistas blogueiros.

Para compor a amostra de blogueiros pesquisados, foram selecionados quinze profissionais que atuavam em seus próprios blogs; posteriormente, foram divididos em dois grupos, baseados em sua relação com os portais e/ou empresas de comunicação: dependentes (A) e independentes (B), sendo que este último grupo possuía uma subdivisão, entre 
blogueiros ligados a portais independentes e aqueles sem vínculo com portais. São eles: Josias de Souza, Juca Kfouri, Leonardo Sakamoto, Reinado Azevedo, Ricardo Kotsho e Ricardo Noblat (Dependentes - ligados a portais de grandes grupos de comunicação); Conceição Oliveira, Renato Rovai, Rodrigo Vianna, Luís Nassif, Luiz Carlos Azenha e Paulo Henrique Amorim (Independentes - ligados a portais também independentes); Altamiro Borges, Altino Machado e Miguel do Rosário (Independentes sem ligação com portais).

A partir dessa divisão, foi feita uma análise geral do perfil dos blogueiros, detalhando seus meios de produção e de subsistência. E, a partir da fala do grupo de jornalistas blogueiros independentes (B), foi detectada a existência de redes de conexão e também a formação de uma mídia contra hegemônica, que evidenciou um enfrentamento às tentativas de controle e censura, além de uma busca por arranjos econômicos alternativos para a subsistência.

Nos blogs, o jornalista não precisa da estrutura de uma empresa de comunicação; pode escrever de qualquer local e, principalmente com isenção, sem a interferência de interesses comerciais e/ou das empresas de comunicação, ideais que, a princípio, remetem à realização de um sonho. Nessa condição, o jornalista se vê como um empreendedor social, "uma alegoria do trabalhador imaginado pelo sistema capitalista, que integra a vocação, no sentido weberiano; a habilidade empreendedora; a capacidade de ser sustentável, no sentido econômico; e uma imagem de felicidade e realização plena" (Casaqui, 2015). Para o autor, essa seria "a interseç̧ão entre a dimensão comunicacional que constitui o espírito do capitalismo contemporâneo e significados atribuídos ao mundo do trabalho, à cultura corporativa" (idem).

Para Schittine (2004), ao contrário dos diaristas virtuais, que se esforçam para se transformarem em formadores de opinião, como colunistas de jornais, os jornalistas encontraram nos blogs uma maneira de fugir um pouco das obrigações da profissão, atraídos, principalmente, pela sensação de liberdade encontrada no novo meio, onde o profissional não se vê cerceado pelo veículo de comunicação no qual trabalha. A começar pelo texto, mais simples e direto, até a sugestão de pauta, tudo pode ser modificado, além de não precisar passar pelas mãos dos editores e redatores. "O jornalista sente falta de ter mais liberdade, mais domínio sobre o próprio texto". (Schittine, 2004, p. 180)

Mas essa liberdade de escrever um texto sem a mediação de uma empresa de comunicação esbarra em dificuldades. Uma delas é o leitor, que muitas vezes é exigente com esse novo texto, que chega até ele sem a mediação de um veículo de imprensa, e pode tornar a convivência difícil. Ou seja, se o assunto não agrada, o blogueiro precisa aprender a lidar com as críticas ou mesmo com a redução de acessos, o que pode prejudicar a sobrevida do blog. Outro problema é a concorrência e a necessidade de manter o blog e seus leitores, principalmente quando o blog é profissional. Trata-se do caráter interativo do novo modo de produção e circulação da notícia. 
O novo meio revitalizou o Jornalismo, trazendo fôlego para aqueles profissionais que estavam cansados das rotinas produtivas dos meios de comunicação tradicionais. Por meio dos blogs, esses jornalistas impactaram a sociedade, trazendo à tona debates em torno da ética, corrupção, gastos e política pública, divulgando e denunciando fatos que não se vê na mídia tradicional.

Para os leitores, trouxe novas visões da notícia, além da possibilidade de interpretação, escolha e até discussão. E, para as empresas de comunicação, um novo desafio. Ao hospedar os blogs nos portais dos grandes jornais brasileiros, esses veículos reconheceram a importância dos blogs e procuraram "se adequar à nova realidade de um mercado de concorrência que se renova sem cessar" (Adghirni, 2008).

As análises demostraram que, de modo geral, os quinze selecionados são profissionais maduros; têm entre 37 anos (Leonardo Sakamoto) e 72 anos (Paulo Henrique Amorim) e uma carreira já consolidada no Jornalismo, o que comprova a hipótese de que reputação, popularidade, credibilidade e visibilidade são valores fundamentais (Recuero, 2009; Dantas, 2014b) para a consolidação profissional na Sociedade em Rede. A motivação dos jornalistas para criarem o próprio blog é bastante variada. As falas mais recorrentes foram que o blog foi adotado por indicação de pessoas mais jovens; por fazerem questão de estarem atualizados tecnologicamente; e ainda pela possibilidade de gerar uma informação diferenciada daquela publicada na grande mídia. Guazina (2013, p. 11) afirma que, para esses jornalistas, "o blog foi uma forma de conciliar com mais liberdade o exercício da profissão jornalística com a percepção sobre o mundo social, a política e o próprio Jornalismo".

A maioria dos blogueiros mantém outras ocupações além do blog; observa-se, no entanto, que o local preferido para escrever e administrar as demandas do blog é na própria residência: "Eu escrevo de casa, na calma da minha casa; às vezes escrevo de madrugada, acompanhado de uma cachaça ou copo de uísque". (Miro Borges, in Lima, 2015, p.175). Ao observar o trabalho dos jornalistas blogueiros, verificamos que estes profissionais levam para 0 blog os mesmos valores apreendidos ao longo da carreira nos veículos tradicionais, mantendo o seu ethos, e até mesmo estabelecendo uma rotina de trabalho semelhante à que mantinham nas redações: "Não vejo nenhuma diferença entre o que eu escolho ou o que eu escolheria, se estivesse trabalhando num jornal" (Noblat, in Lima, 2015, p. 177).

O trabalho do jornalista blogueiro é, quase sempre, solitário. Alguns dispõem de pequenas equipes ou pouco colaboradores. A relação com os leitores é direta e instantânea. Os leitores estão conectados e dispostos a participar do dia a dia dos noticiários, principalmente nos blogs. Elogiam, dão sugestões, mas também criticam e até ofendem os jornalistas blogueiros. A sociedade em rede trouxe o melhor, mas também o pior lado da comunicação direta. Precisaram criar novas prescrições e aprender a lidar com essa mudança, que foi bastante impactante para o profissional: "Você tem alguns leitores agressivos, alguns leitores fiéis, que colaboram e tudo, mas que se sentem, às vezes, donos do pedaço. Então, começam 
a agredir outros leitores. É um ponto que você tem que colocar." (Luís Nassif, in Lima, 2015, p. 182).

Alguns depoimentos demonstraram que os jornalistas buscam o novo meio procurando encontrar a autonomia e a independência que não encontraram nos meios tradicionais de comunicação, confirmando uma de nossas hipóteses. "No Jornalismo convencional nunca me senti livre. O Jornalismo convencional é um Jornalismo comercial. E quem disser que é livre mente. Não existe isso. Você é livre se você pensar como o patrão. No Brasil funciona assim: você tem toda a liberdade de pensar como o seu patrão pensa. Na internet sim." (Paulo Henrique Amorim, in Lima, 2015, p. 183).

Mas a total independência e liberdade de expressão desejada pelos blogueiros é ilusória. Como sobreviver, dentro da lógica capitalista, sem um meio de subsistência?

Os jornalistas ligados aos portais de grandes empresas de comunicação mantêm uma relação contratual estável, recebem salários e são considerados trabalhadores produtivos. Já aqueles profissionais que não têm esse vínculo, nem a estabilidade contratual, são improdutivos perante o sistema, ou seja, para a reprodução do capital.

\section{Considerações finais}

A problematização apresentada neste artigo buscou evidenciar, de um lado, o uso dos números como uma estratégia persuasiva para a construção de sentido no discurso jornalístico, dando-Ihe objetividade, e a forma como esse recurso revela as rotinas produtivas. Pôde-se compreender a forma como o jornalista submete a própria liberdade de expressão à liberdade de imprensa da empresa, e sua ideologia, valendo-se de recursos simbólicos, como os números, para embaçar o foco da notícia e sua relevância enquanto fato social.

A linha editorial incorporada pelo profissional naturaliza-se como procedimento afeito ao Jornalismo, como parte da objetividade. A pressão do tempo, o excesso de trabalho, a precarização da profissão são elementos que contribuem para o jornalista (com ou sem vínculos empregatícios) não se contrapor às lógicas editoriais. Para ele, a palavra já aparece domada. Esse silêncio da grande mídia frente a certos temas é manifestado no microssocial através da persuasão e do convencimento, pois o trabalho do jornalista é tão vilipendiado, com muitos adotando o ponto de vista dos "patrões".

Tem-se, então, a forma como as instituições da sociedade civil estão à mercê dos interesses corporativos e como o sujeito aparece assujeitado na luta de classe. Nota-se, sobretudo, a falta de compromisso com o aprofundamento da democracia e o fato de como o mundo do trabalho do jornalista produz um Jornalismo tão precário, instável e individualista quanto as próprias condições para o exercício da profissão e para a produção da notícia. Qual seria, então, o caminho para o Jornalismo?

Ainda estamos em pleno processo de transição da atividade que, em sua essência, nasceu como difusora de informação e se transformou em meio de contra hegemonia. No 
ambiente das redes sociais dos blogs tem-se uma tentativa de resgatar o papel da informação e, sobretudo, do Jornalismo como difusor da notícia e meio contra hegemônico - apesar de recentes denúncias de financiamento turvarem esse cenário.

Acredita-se que só em um contexto isento e autônomo de produção noticiosa - seja qual for o aparato técnico e a plataforma tecnológica, bem como os retornos financeiros - é possível haver dedicação mais profunda à interpretação, à criação de relações e à tradução das informações, comunicando para o conhecimento, sem comprometer os sentidos. Portanto, cabe ao jornalista buscar rearranjos profissionais e de sustentação financeira que lhe permitam desenvolver um trabalho com o olhar fixo nos valores que identificam o Jornalismo como prática social voltada aos direitos do cidadão à informação, rumo à consolidação da democracia.

\section{Referências}

ADGHIRNI, Zélia L (2008). Blogs: a invasão dos profanos do mundo digital na esfera sagrada do jornalismo. Anais do VI SBPJOR, São Paulo. Disponível em:

http://sbpjor.kamotini.kinghost.net/sbpjor/admjor/arquivos/coordenada12zelialealadghirni.pdf Acesso em 05/04/2013.

BULLA, Olívia (2015). A evidência dos números no discurso jornalístico através das relações de comunicação e trabalho. 2015. 165 f. Dissertação (Mestrado em Ciências da Comunicação) Escola de Comunicações e Artes, Universidade de São Paulo. Disponível em http://www.teses.usp.br/teses/disponiveis/27/27152/tde-13112015-094109/pt-br.php_Acesso em 06/12/2015.

CASTELLS, Manuel (1999). A sociedade em rede. A era da informação: economia, sociedade e cultura; v.1. São Paulo: Paz e Terra.

CHAUÍ, Marilena (2013). As manifestações de junho de 2013 em São Paulo. Revista Teoria e Debate, edição 113, 27 de junho de 2013. Disponível em http://www.teoriaedebate.org.br/materias/nacional/manifestacoes-de-junho-de-2013-nacidade-de-sao-paulo?page=full Acesso em 29/11/2015.

DANTAS, Marcos (2014). Mais-valia 2.0: produção e apropriação de valor nas redes do capital. Revista Eptic Online. Vol. 16, n.2, p. 89 a 112, mai - ago 2014. Disponível em http://www.seer.ufs.br/index.php/eptic/article/view/2167 Acesso em 29/10/2014

DEBORD, Guy (2003). A sociedade do espetáculo. E-book digitalizado por Coletivo Periferia e e-books Brasil. Disponível em http://www.ebooksbrasil.org/adobeebook/socespetaculo.pdf. Acesso em 31/10/2014

FREDERICO, Celso (2013). Da periferia ao centro: cultura e política em tempos pósmodernos. Estud. av.[online]. 2013, vol. 27, n. 79, pp. 239-255.

GUAZINA, Liziane Soares (2013). Jornalismo que tem lado: o caso dos blogueiros brasileiros "progressistas". BRAZILIAN JOURNALISM RESEARCH - Volume 9 - Número 2 - 2013. Disponível em http://bjr.sbpjor.org.br/bjr/article/view/545/492 Acesso em 09/01/2015.

HUWS, Ursula Elin (2007). O que mudou foi a divisão do trabalho (Entrevista). Revista do Instituto Humanitas Unisinos - IHU (On-line). Ano VII, N. 216, 23/04/2007. Disponível em http://www.ihuonline.unisinos.br/index.php?option=com content\&view=article\&id $=854 \&$ secao $=216$. Acesso em 03/12/2014 
LIMA, Cláudia do Carmo Nonato (2015). Jornalistas, blogueiros, migrantes da comunicação: em busca de novos arranjos econômicos para o trabalho jornalístico com maior autonomia e liberdade de expressão. 2015.250 f. Tese (Doutorado em Ciências da Comunicação) - Escola de Comunicações e Artes, Universidade de São Paulo. Disponível em http://www.teses.usp.br/teses/disponiveis/27/27152/tde-26062015-112522/pt-br.php

MARTINO, Luís Mauro Sá (2009). Teoria da Comunicação: ideias, conceitos e métodos. Petrópolis, RJ: Vozes, 2009.

MARX, K., ENGELS, F. (2010). Cultura, arte e literatura. Textos escolhidos. São Paulo: Expressão popular.

PULITI, Paula. (2013). O juro da notícia. Florianópolis: Insular.

RECUERO, Raquel (2009). Redes sociais na internet. Porto Alegre: Sulina (Coleção Cibercultura)

RÜDIGER, Francisco (2011). As teorias da comunicação. Porto Alegre: Penso.

SCHITTINE, Denise (2004). Blog: comunicação e escrita íntima na internet. Rio de Janeiro: Civilização Brasileira.

SEIFE, Charles (2012). Os números (não) mentem - Como a matemática pode ser usada para enganar você. Rio de Janeiro: Zahar. 